\title{
Measuring the Market Power of Finnish Food Retailers
}

\author{
Xavier Ir ${ }^{11}$ and Xing Liu ${ }^{11}$ \\ 1) Natural Resources Institute Finland (Luke), Economics and Society Research Unit, Koetilantie 5, \\ 00790 Helsinki,emails: xavier.irz@luke.fi and xing.liu@luke.fi
}

\begin{abstract}
The last twenty years have witnessed substantial changes in retailing across most of Europe. The concentration of retail buying has increased considerably, and this general evolution has been particularly significant in Finland. For example, the top three supermarkets in Finland currently share $88 \%$ of the grocery market. As established by the EU commission, a common consequence of high concentration in retailing is a growing power of supermarkets over their suppliers, which may distort competition with upstream suppliers (food processors, farmers). For instance, retailers may use their power to push costs and risks up the supply chain, with the result that smallholder suppliers may be squeezed out. Downstream, consumers may also be affected through less innovation, a reduction in choice and higher prices in the long-run.

However, while high concentration is a necessary condition for the existence of market power, it is not sufficient. It is also well known that growing marketing margins, or the imperfect transmission of prices along the food chain, may or may not be related to market power. Thus, the purpose of the paper is to measure market power directly by using the conceptual framework developed in the New Empirical Industrial Organisation. The paper presents a model suitable for that purpose and compatible with the highly aggregated data available in Finland. The empirical application uses data from Tilastokeskus and considers the three supply chains for cereal products, meat and dairy.

The results provide evidence that retailers in Finland have significant market power, particularly in the cereals and meat sectors, and that the related distortions have an economically important impact on prices offered to upstream suppliers and downstream consumers. However, the robustness of the results is limited by the nature of the available data as well as the simplifying assumptions of the model. Further, it is evident that other factors, and above all wages in retail, are also important in explaining growing retail margins in Finland.
\end{abstract}

Key words: market power; industrial concentration; industrial organization; food retail; marketing margin Paper prepared for presentation at Maataloustieteen päivien 2016, Helsinki, 12-13.1.2016 


\section{Introduction}

The last twenty years have witnessed substantial changes in retailing across Europe. In particular, the increased prevalence of category management, significant investments in new technology and improved logistics have enabled supermarkets in European countries to acquire an increasing share of grocery markets. Retail buying is becoming increasingly concentrated, in part because retailers have become very large sellers and in part because retailers combine their buying activities. Behind those general trends, variations prevail across countries. In Finland, the top three supermarkets share $88 \%$ of the grocery market, which is the highest proportion among all the countries for which have found data, and the Finnish retail market has commonly been described as a near-duopoly (1). This extreme situation generates concerns among various stakeholder groups, because high market concentration is commonly associated with the exercise of market power (2). Continuously increasing power of supermarkets over their suppliers may distort competition in upstream markets. For instance, suppliers may use that power to push the costs and risks of business down the supply chain, thereby squeezing out smallholder suppliers. Downstream from retailers, consumers may also be affected through less innovation, reduction of choice and higher prices in the long-run (3).

High concentration, however, does not necessarily result in market power, as articulated in the economic theory of contestable markets (4), which argues that the threat of competition by new entrants may be sufficient to ensure efficiency. If incumbent firms made use of their market power to charge excessive prices and extract a rent from their customers, entry from competitors would be automatically triggered, reducing profits of the incumbent firms. Those firms, being aware of this mechanism, apply a form of self-restraint in pricing to avert entry from competitors. Other forces making it less likely for Finnish food retailers to exert excessive market power include globalization and the increased trade in processed food products, as exemplified in Finland by the arrival of the discount German retailer Lidl on the Finnish market at the turn of the century (5). A recent study (1) also points to the corporate structure of one of the leading two retailers, which is a cooperative, as a mitigating factor.

Thus, theory alone remains inconclusive regarding the connection between market power and level of concentration, and the question therefore needs to be investigated empirically. Early efforts within the structural-conducted-performance (SCP) approach sought to relate econometrically measures of industrial concentration, such as the Herfindahl-Hirshman index (HHI), to indicators of profitability (e.g., price-cost margin, Lerner index). However, while this simple approach may help generate hypotheses and set the scene, its relative lack of theoretical foundations and static nature represent major weaknesses that prevents the identification of causal effects. Thus, in a Finnish context, while it is clear that the process of retailer concentration has accompanied growth in the marketing margin, that evolution does not provide evidence of non-competitive behaviour. For instance, one could argue that efficient retailers acquire market shares over time because of their low-cost offering rather than market power.

In response to those shortcomings of the SCP approach, two alternatives have been developed to investigate imperfect competition. The first one concentrates on the analysis of price transmission horizontally (i.e., across regions) and vertically (i.e., along the value chain) so as to detect anomalies (e.g., partial, slow, asymmetric transmission). It has been popular because of its minimal data requirements (i.e., two price series in its most basic form) and intuitive appeal since it resonates with the often expressed concern that reductions in farm prices are not passed on to consumers in the form of lower retail prices. Several applications to Finnish food markets have been published (6) but the approach has some limitations because interpreting imperfect price transmission remains difficult, as it may be caused by market power but also other factors such as adjustments costs (due to relabeling costs, advertising, etc.)

The second alternative to SCP corresponds to the New Empirical Industrial Organization (NEIO), whose main aim is to measure market power directly instead of using published proxies as in the NCP approach (7). Thus, while growing margins coincidental with industry concentration and imperfect price transmission may or may not be indicative of market power, the NEIO generates firmer conclusions regarding the presence of market power and its magnitude. Other advantageous characteristics include the fact that NEIO focuses on multiple aspects of market conduct such as the behavior and strategic reactions of firms in an industry. Thus, the NEIO addresses the weak theoretical foundation of the SCP and time series approaches by deriving empirical models from fully consistent microeconomic theory (8). 
The NEIO approach has been applied extensively to the analysis of market power within the food chain but most of the studies to date have focused on the relationship between primary producers (e.g., pig farmers) and food processors (e.g., slaughter houses), while the retail sector has received less attention. This is explained by the complexity of modeling the operation of retailers due to two specific characteristics: 1- the potential presence of market power both upstream and downstream; and 2- the breadth of the products sold (i.e., all foods). However, within the EU, the influence of retailers on specific markets has been investigated, including: dairy and meat in France (9); three groups of dairy products in Austria (10); beef and pork in Germany (11); and the PDO cheese market in Italy (12). In Finland, the economic and social effects of imbalanced bargaining power between retailers and food processors are increasingly recognized ${ }^{1}$. Many studies have investigated marketing margins and price formation in the food chain $(13,14,15,16)$ but empirical research seeking explicity to measure market power is limited. A notable exception is the study of Aalto-Settälä (10) that concluded that the main purpose of large grocery retail mergers was to gain market power rather than efficiency, but the twenty-year old data limits the relevance of that study. Thus, the objective of this paper is to fill the outlined research gap by measuring the market power (MP) of Finnish food retailers using NEIO methods.

\section{Theory and empirical Model}

The firm-level model

We use the framework proposed by (9), who extended the oligopoly model of (17). We assume that the potentially imperfectly competitive retail industry is made up of $N$ firms, which distribute $M$ homogeneous final goods. The retail firms purchase the $M$ goods from wholesalers and combine them with additional inputs (e.g., labour, retail premises) to produce the final food products that are made available and sold to consumers. The food retail firms are oligopolistic towards consumers and oligopsonistic towards suppliers, i.e. they have some level of market power both upstream and downstream in the food chain. However, retailers do not exert market power in the markets for non-food inputs, such as labour, capital or energy. The production technology of retailers is restricted to be of the fixed-proportions type in terms of the food inputs, which fits the intuition that to produce one unit of a final-food product requires a fixed quantity (at least one) of the corresponding wholesale food product. This last assumption implies the following form for the dual cost function of any retail firm $j: C^{j}\left(Q^{j}, w, \sigma, F C^{j}\right)=\left(\sum_{i=1}^{M} w_{i} Q_{i}^{j}\right)+C^{j}\left(Q^{j}, \sigma\right)+F C^{j}$, where $w$ is the price vector of the $M$ wholesale goods, $Q^{j}$ is the corresponding vector of quantities of the wholesale (and retail) goods, $\sigma$ is the vector of prices of the non-food inputs used by retailers, and $F C^{j}$ denotes the fixed cost of retailer $j$. The market environment is described by the sector-level ${ }^{2}$ inverse-supply functions $w_{i}=I S\left(Q_{i}^{S}, Y\right)$ and inverse-demand functions $r_{i}=I D\left(Q^{d}, Z\right)$ for each good $i$, where $r$ is the vector of the $M$ retail prices; $Q^{d}$ and $Q^{s}$ denote the industry-level quantities of each of the $M$ food products (and in equilibrium $\left.Q^{d}=Q^{s}\right) ; Z$ and $Y$ are vectors of exogenous shift variables of the inverse demand and inverse supply functions. An important assumption, which is embedded in the previous equations, is that all $M$ retail prices are demand related, i.e. variations in the quantity demanded of any final good impacts all $M$ retail prices. By contrast, the $M$ wholesale goods are supply independent, i.e. the wholesale price of good $i$ only depends on the supply quantity of good $i$. The profit of retail firm $j$ is denoted $\Pi^{j}$ and is expressed as: $\Pi^{j}=\sum_{i=1}^{M}\left(r_{i} Q_{i}^{j}-w_{i} Q_{i}^{j}\right)-C^{j}\left(Q^{j}, \sigma\right)-F C^{j}$. That profit is maximized by firm $j$ by choosing the quantity vector $Q^{j}$ subject to two types of relationships: 1 . Conjectural variations measuring the response, in quantity terms, of competitors to any change in the supply of firm $j$. This is summarized by the $M x M$ parameters $\theta_{l i}^{j}=\left(\partial Q_{l} / \partial Q_{i}^{j}\right) /\left(\partial Q_{i}^{j} / \partial Q_{l}\right)$, which quantify the response of industry-level quantities to a change in supply of good $i$ by firm $j$; and 2 - The market equilibrium conditions. The firm-level first order conditions derived by (9) are:

$$
r_{i}-w_{i}=M C^{j}(\sigma)+\sum_{m=1}^{M} \gamma_{m m} \cdot \theta_{m i}^{j} \cdot w_{m} \cdot\left(\frac{Q_{m}^{j *}}{Q_{i}^{j *}}\right)-\sum_{m=1}^{M} \sum_{l=1}^{M} \varepsilon_{m l} \cdot \theta_{l i}^{j} r_{m} \cdot\left(\frac{Q_{m}^{j *}}{Q_{i}^{j *}}\right)
$$

\footnotetext{
${ }^{1}$ Finnish competition Authority (2012). Study on Trade in Groceries. FCA reports 1/2012.

${ }^{2}$ Unless specified otherwise, sector-level variables are denoted without any subscript, while firm-level variables are identified with subscript $j$.
} 
where $\gamma_{m m}=\left(\frac{\partial w_{m}}{\partial Q_{m}}\right) \cdot\left(\frac{Q_{m}}{w_{m}}\right)$ is the elasticity of inverse supply of the $m$-th wholesale good with respect to its own quantity and $\varepsilon_{m l}=\left(\frac{\partial p_{m}}{\partial Q_{l}}\right) \cdot\left(\frac{Q_{l}}{p_{m}}\right)$ is the elasticity of inverse demand for the $m$-th final good with respect to the quantity of the $l$-th final good. Thus, the marketing margin of retail firm $j$ is equal to a marginal cost function and the sum of both a demand-side term and a supply-side term. The fact that the conjectural-variation parameters are equal in the supply and demand terms (i.e., are described by the same set of parameters $\theta$ ) is linked to the assumption of fixed proportions in the use of wholesale foods in order to produce final foods.

The conjectural-variation elasticities $\theta_{m i}$ are the key conduct parameters of this model that relate to market power. Hence, (9) show that, when assuming no cross-product conjectural variations (i.e., $\theta_{l i}^{j}=$ 0 for $(\neq i)$ :

- All conjectural elasticities are nil for a perfectly competitive firm: $\theta_{l i}^{j}=0$ for any / and any $i$.

- If the firm is a monopolist-monopsonist: $\theta_{i i}^{j}=1$ for any good $i$, while all cross conjectural elasticities are equal to zero.

- If firm $j$ enjoys some market power that falls short of the monopolist-monopsonist situation, $\theta_{i i}^{j} \neq 0$ for some goods, and some cross-product conjectural variations may also be different from zero.

\section{The empirical sector-level model}

The unavailability of retailer-level data in Finland represents a key difficulty in the analysis of market power in the food chain. Thus, equation (1) is not directly estimable, and, instead, must be aggregated across firms in order to derive empirically tractable relationships. This in turn requires a number of simplifying assumptions: first, the variable cost function of all retailers is of the Gorman-Polar type, which implies that all retailers have the same marginal cost; second, all firms have the same conjectural variations in equilibrium, i.e. for any two goods $I$ and $i$ and two firms $j$ and $k, \theta_{l i}^{j}=\theta_{l i}^{k}=\theta_{l i}$. Under those assumptions, the sector-level equilibrium condition equivalent to the firm-level condition (1) is:

$$
r_{i}-w_{i}=M C^{j}(\sigma)+\sum_{m=1}^{M} \gamma_{m m} \cdot \theta_{m i} \cdot w_{m} \cdot\left(\frac{Q_{m}^{*}}{Q_{i}^{*}}\right)-\sum_{m=1}^{M} \sum_{l=1}^{M} \varepsilon_{m l} \cdot \theta_{l i} r_{m} \cdot\left(\frac{Q_{m}^{*}}{Q_{i}^{*}}\right)
$$

In the empirical application, we estimated several variations of this model that have been proposed in the literature. Some variants are simply embedded in (2), e.g. assuming no cross-product conjectural variations. Others rely on different assumptions. Hence, Salhofer et al. (18) developed a model allowing for different levels of market power towards input suppliers and consumers.

The full specification of the empirical model assumes a linear marginal cost function in equations (2): $M C=\alpha_{1} \sigma_{1}+\alpha_{2} \sigma_{2}+\alpha_{3} \sigma_{3}$, where $\sigma_{1}, \sigma_{2}, \sigma_{3}$ are proxy prices for the non-food production factors of retailers (labour, energy and capital services).

Data

Estimation of the model requires a variety of data. The left hand-side of the estimable equation (2) is the absolute level of the retail gross margin, which has been derived elsewhere in the same project for the period 2000-2013 for three sectors: meat, dairy, and cereal products ${ }^{3}$. The fact that those margins are only available annually for a short period of time constrains heavily the empirical work, since 14 observations give limited degrees of freedom for the statistical analysis. The percentage gross margins are combined with retail price indices to infer commensurate wholesale price indices. Consumption volumes are measured by constant-price expenditure on each food category as reported in the Finnish National Accounts and available from the FinStat database of the Finnish Statistical Institute ${ }^{4}$. The same database gives the nominal consumption figures, and taking the ratio of the nominal and real variables defines a

\footnotetext{
${ }^{3}$ We thank Kyösti Arovuori from PTT for providing those margins. Importantly, the dependent variable is the absolute difference between retail and wholesale prices, which means that using two price indices is not possible.

${ }^{4}$ The StatFin database is available online from the Finnish statistical institute at: http://pxnet2.stat.fi/PXWeb/pxweb/fi/StatFin/. The path to the nominal and real consumption volumes is kansantalous/kansantalouden tilinpito/yksityinen kulutus 75-2013, or directly from the following link: http://pxweb2.stat.fi/database/StatFin/kan/vtp/vtp_fi.asp
} 
retail price index $(19)^{5}$. The wage rate is measured by an index of wages and salaries reported in FinStat for the category "Retail sale in non-specialised stores $(4711,472)^{\prime \prime}$, while the price of energy is proxied by the producer price index of the energy sector in the same database ${ }^{7}$. The price of capital is measured by the interest rate available from the online database of the European Central Bank (ECB). ${ }^{8}$

\section{Results}

Given the limited number of observations, the demand and supply elasticities were set before estimation of equation (2). Reasonably recent own and cross-price demand elasticities for the three food groups have been reported in (20) and are used to calibrate the model. On the supply side, we estimated the supply functions of wholesalers in the three sectors using a simple log-linear functional form and a twostage least squares (2SLS) procedure with a constant and one-year lagged wholesale prices as instruments. The implied supply elasticities were $0.57,0.07$ and 1.02 for the grain, meat and dairy sectors respectively.

Table 1 presents the estimation results of a simplified version of model (2) where the only non-food input considered was labour. The model was estimated in first-difference using a three-stage least squares procedure with one-year lagged prices and quantities used as instruments. Given that the data was firstdifferenced, the values of the R-squared statistics indicate a reasonable fit, although the model explains variations in the retail margin for the meat product group much better than for the dairy product group. The values of the Durbin-Watson statistics imply no major problem of autocorrelation. Many, but not all, of the coefficient estimates are statistically significant, but here again there is evidence that the model performs much better for the meat equation than the dairy equation. In the case of the former, we observe in particular that wages have a significant impact on the retail margin for meat products, and that the three cross-conjectural variation (i.e., market power) coefficients are statistically significant.

\begin{tabular}{|c|c|c|c|c|c|}
\hline \multicolumn{2}{|c|}{$\begin{array}{l}\text { Margin } \\
\text { Equation }\end{array}$} & \multirow{2}{*}{$\begin{array}{c}\begin{array}{c}\text { Estimated } \\
\text { Coefficient }\end{array} \\
0.011\end{array}$} & \multirow{2}{*}{$\begin{array}{c}\text { P-Value } \\
0.219\end{array}$} & \multirow{2}{*}{$\begin{array}{l}\mathbf{R 2} \\
0.48\end{array}$} & \multirow{2}{*}{$\begin{array}{r}\text { DW } \\
2.00\end{array}$} \\
\hline Grains & Trend & & & & \\
\hline & Wages & -0.001 & 0.690 & & \\
\hline & $\theta c c$ & -0.027 & 0.002 & & \\
\hline & $\theta c d$ & -0.010 & 0.085 & & \\
\hline & $\theta \mathrm{cm}$ & -0.019 & 0.198 & & \\
\hline \multirow[t]{5}{*}{ Dairy } & Trend & 0.001 & 0.965 & 0.16 & 2.21 \\
\hline & Wages & 0.003 & 0.641 & & \\
\hline & $\theta c c$ & -0.025 & 0.237 & & \\
\hline & $\theta c d$ & -0.004 & 0.741 & & \\
\hline & $\theta \mathrm{cm}$ & -0.013 & 0.716 & & \\
\hline \multirow[t]{5}{*}{ Meat } & Trend & -0.035 & 0.005 & 0.64 & 1.96 \\
\hline & Wages & 0.009 & 0.013 & & \\
\hline & $\theta c c$ & -0.038 & 0.010 & & \\
\hline & $\theta c d$ & -0.022 & 0.010 & & \\
\hline & $\theta \mathrm{cm}$ & -0.076 & 0.003 & & \\
\hline
\end{tabular}

Table 1: estimation results

The coefficients in Table 1 are not directly interpretable, so Table 2 presents the results of simple statistical tests. We find that the hypothesis that Finnish retailers have no market power is strongly rejected when considering the food sector as a whole, but that the situation varies across sub-sectors. Market power is evident from the data in the meat and cereals sectors, but not in the dairy sector. Table 2 also confirms that economic forces not related to competition are also important determinants of retail margins, including wages and other factors captured by the trend variable.

\footnotetext{
${ }^{5}$ Equivalently, retail price indices are available from Eurostat at: http://ec.europa.eu/eurostat/data/database the prices/HICP/annual. We have checked that the two sets of retail prices coincide almost exactly.

${ }^{6}$ Path: Palkat ja työvoimakustannukset/Palkkasummakuvaajat

${ }^{7}$ Path: prices and costs/producer price indices/Producer Price Indices 2010=100 (TOL2008)/ENERGY MIG5

${ }^{8}$ ECB data warehouse: http://sdw.ecb.europa.eu/, path: long term interest rates, monthly, arithmetic average
} 


\begin{tabular}{cccl}
\hline Null Hypothesis & Chi-squared Statistics & P-value & Conclusion \\
\hline No market power & & & \\
All sectors & 6.98 & 0.001 & Reject strongly \\
Cereals & 12.28 & 0.006 & Reject strongly \\
Dairy & 1.51 & 0.67 & Accept \\
Meat & 12.1 & 0.007 & Reject strongly \\
No wage effect & 6.98 & 0.071 & Reject \\
No trend effect & 10.84 & 0.012 & Reject strongly \\
\hline
\end{tabular}

Table 3: Results of statistical tests

Finally, to establish whether market power is economically important, Table 3 presents a Lerner-like index $(p-w-M C) /(p-w)$ as proposed by (9). The index characterises in percentage terms the difference between the observed margin and the margin that would prevail under perfect competition. In the cereals sector, where the tests showed that market power was statistically significant, we find that deviation from perfect competition raises the retail margin considerably (i.e., in the range of 60\%). In the meat sector, the negative values for the first four years appear somewhat anomalous, as they imply below marginal cost pricing by retailers. While as explained by (18) this is a possibility if retailers choose to cross-subsidize some products when defining their pricing strategies, the negative Lerner indices invite caution when interpreting the estimation results. However, since 2008, we find that retailers' market power has raised the marketing margin by five to 14 percent. The results for the dairy sector also indicate that departure from competition raises retailers' marketing margins considerably, but one needs to keep in mind that the market power coefficients were not significant for this equation.

\begin{tabular}{cccc}
\hline Year & Dairy & Meat & Cereals \\
\hline $\mathbf{2 0 0 0}$ & $5.3 \%$ & $-22.8 \%$ & $59.5 \%$ \\
$\mathbf{2 0 0 1}$ & $18.8 \%$ & $-12.9 \%$ & $61.5 \%$ \\
$\mathbf{2 0 0 2}$ & $19.0 \%$ & $-24.7 \%$ & $58.8 \%$ \\
$\mathbf{2 0 0 3}$ & $24.6 \%$ & $-9.8 \%$ & $60.7 \%$ \\
$\mathbf{2 0 0 4}$ & $30.1 \%$ & $-1.1 \%$ & $62.4 \%$ \\
$\mathbf{2 0 0 5}$ & $19.1 \%$ & $-0.6 \%$ & $57.2 \%$ \\
$\mathbf{2 0 0 6}$ & $19.7 \%$ & $-1.8 \%$ & $57.0 \%$ \\
$\mathbf{2 0 0 7}$ & $21.0 \%$ & $-5.4 \%$ & $55.5 \%$ \\
$\mathbf{2 0 0 8}$ & $27.4 \%$ & $5.0 \%$ & $62.6 \%$ \\
$\mathbf{2 0 0 9}$ & $31.3 \%$ & $8.5 \%$ & $62.4 \%$ \\
$\mathbf{2 0 1 0}$ & $31.9 \%$ & $14.2 \%$ & $62.6 \%$ \\
$\mathbf{2 0 1 1}$ & $32.8 \%$ & $17.3 \%$ & $61.8 \%$ \\
$\mathbf{2 0 1 2}$ & $29.8 \%$ & $13.1 \%$ & $63.1 \%$ \\
$\mathbf{2 0 1 3}$ & $33.8 \%$ & $14.0 \%$ & $64.6 \%$ \\
\hline \hline
\end{tabular}

Table 4: Lerner-like index

\section{Discussion and conclusion}

The paper presents only one set of results because of length limitations but we have estimated a variety of alternative specifications in order to assess the robustness of the findings. The general conclusions from this work are summarized as follows. The aggregate and annual nature of the time-series as well as the short time spam over which retail margins are available make it difficult to establish accurately the magnitude by which retail margins may be inflated due to retailers' market power. Nevertheless, under most specifications, the data supports the presence of market power as well as an increasing trend in the effect of market power on retail margins. This general conclusion applies particularly to the meat and cereals sectors, while in the dairy sector the evidence is not as strong. We may postulate that the high degree of industrial concentration among dairy processors in Finland is a factor limiting the market power of retailers in the sector. Calculation of the Lerner index further establishes that market power in the cereals and meat sectors is not only significant in a statistical sense but also economically important. 
While indicating the relevance of market power in explaining growing retail margins in Finland, the analysis also reveals the importance of other factors that are often overlooked, incuding wages of the workers employed in retail. The fact that the wage index for that labour has grown much faster than food prices over the last 15 years has contributed substantially to the expansion of retail margins. Here, the findings confirm those of a previous study that investigated the determinants of food price inflation in Finland (21).

\section{References}

1. Kronqvist T. Consumer-owned retail cooperative in duopoly with horizontally differentiated goods: a Finnish experience [dissertation]. Aalto University, Department of Economics, Helsinki School of Economics; 2010.

2. Burt SL, Sparks L. Power and competition in the UK retail grocery market. Br J Manage. 2003;14(3):237-54.

3. Dobson PW, Waterson M. Countervailing power and consumer prices. The Economic Journal. 1997:418-30.

4. Baumol WJ, Panzar JC, Willig RD, Bailey EE, Fischer D, Fischer D. Contestable markets and the theory of industry structure. . 1982.

5. Jansik C, Niemi J, Ahlstedt J. Retailer brands speed up food imports from Germany. Finnish Agriculture and Rural Industries 2015. 2015:18-21.

6. Liu X. Horizontal price transmission of the Finnish meat sector with major EU players. MTT Discussion Papers. 2011;1:2011.

7. Perloff JM, Karp LS, Golan A. Estimating market power and strategies. Cambridge University Press; 2007.

8. Digal LN, Ahmadi-Esfahani FZ. Market power analysis in the retail food industry: a survey of methods. Aust J Agric Resour Econ. 2002;46(4):559-84.

9. Gohin A, Guyomard H. Measuring market power for food retail activities: French evidence. Journal of Agricultural Economics. 2000;51(2):181-95.

10. Aalto-Setälä V. The effect of concentration and market power on food prices: evidence from Finland. J Retail. 2002 0;78(3):207-16.

11. Anders SM. Imperfect competition in German food retailing: Evidence from state level data. Atl Econ J. 2008;36(4):441-54.

12. Sckokai P, Soregaroli C, Moro D. Estimating market power by retailers in a dynamic framework: the Italian PDO cheese market. Journal of Agricultural Economics. 2013;64(1):33-53.

13. Peltoniemi A, Arovuori K, Niemi J, Pyykkönen P. Lihasektorin hintarakenteet. . 2014.

14. Peltoniemi A, Arovuori K, Niemi J, Pyykkönen P. Maitosektorin hintarakenteet. . 2015.

15. Kotilainen M, Koski H, Mankinen R, Rantala O. Elintarvikkeiden hinnanmuodostus ja markkinoiden toimivuus. 2010.

16. Niemi J, Jansik C. The behaviour of prices and marketing margins of selected food products in Finland. The Nordic-Baltic economic conference'Value Added in the Food Chain'; ee; 2006.

17. Schroeter J, Azzam A. Measuring market power in multi-product oligopolies: the US meat industry. Appl Econ. 1990;22(10):1365-76.

18. Salhofer K, Tribl C, Sinabell F. Market power in Austrian food retailing: the case of milk products. Empirica. 2012;39(1):109-22.

19. Edgerton DL. The econometrics of demand systems : with applications to food demand in the Nordic countries. Dordrecht [Netherlands]; Boston [Mass.]: Kluwer Academic Publishers; 1996.

20. Irz X, Kuosmanen N. Explaining growth in demand for dairy products in Finland: an econometric analysis. Food Economics. 2013;9(sup5):47-56.

21. Irz X, Niemi J, Liu X. Determinants of food price inflation in Finland-The role of energy. Energy Policy. 2013;63:656-63. 